\title{
La vestimenta femenina en la Costa Central del Perú durante el Período Intermedio Tardío
}

\section{RESUMEN}

Los vestidos femeninos del Período Intermedio Tardío (1000 - 1470 DC) hallados en la Costa Central peruana se definen por la posición horizontal de las aberturas para los brazos y la cabeza, a diferencia de las aberturas verticales de los trajes masculinos. En este artículo se presenta la clasificación y el análisis de varios de estos vestidos femeninos, pertenecientes a la colección textil del Museo Nacional de Arqueología, Antropología e Historia del Perú.

Palabras claves: Costa Central peruana - Periodo Intermedio Tardio - vestimenta femenina.

\section{ABSTRACT}

Feminine dresses of the Late Intermediate Period (1000 1470 AD), from Peruvian Central Coast, are defined by the horizontal position of neckslit and armholes, in contrast to its vertical position in masculine garment. This paper presents the classification and analysis of several female dresses, belonging to the textile collection of the Museo Nacional de Arqueología, Antropología e Historia del Perú.

Keywords: Peruvian Central Coast - Late Intermediate Period - feminine dresses.

\section{Introducción}

Para el Período Intermedio Tardío de la Costa Central peruana se ha definido un tipo de vestimenta femenina ${ }^{2}$ que consiste en una camisa cerrada con aberturas horizontales para los brazos y el cuello, con costuras en la zona correspondiente a los hombros, y eventuales plegaduras. La particularidad de estos vestidos es que presentan costuras para el cierre, haciendo innecesario el uso

1 Universidad Nacional Mayor de San Marcos, Lima. Email: apontedelia@hotmail.com

2 Sobre los vestidos femeninos con aberturas horizontales para los brazos y la cabeza, provenientes de la Costa Central peruana véanse: Gayton (1955), Emery y King (1957), Stummer y Gayton (1958), Vanstan (1961), Desrosiers y Pulini (1992) y Prümers (1998). de alfileres o tupus para este fin. Se sostiene que son prendas femeninas debido a que, en los casos donde ha sido posible determinar su contexto, se ha encontrado que formaban parte del ajuar de tumbas de mujeres, en su mayoría de filiación cultural Chancay (Figura 1).

\section{Clasificación de la muestra}

Los tejidos que componen la base de este estudio se encuentran en el Depósito Textil del Museo Nacional de Arqueología, Antropología e Historia del Perú, mientras sus datos de contexto se encuentran en el Archivo Documental del mismo Museo. Todos ellos presentan las características siguientes: disposición horizontal de las urdimbres, aberturas horizontales para los brazos y la cabeza y costuras de cierre. La muestra está compuesta por 21 tejidos, los cuales se han clasificado atendiendo a su manufactura, decoración y diseño, como sigue:

Vestidos miniatura

Monocromos

De dos bandas horizontales

1 ejemplar

De tres bandas horizontales

6 ejemplares

6 ejemplares

Vestidos de una pieza

4 ejemplares

Vestidos de dos piezas

3 ejemplares

Vestidos de tres piezas

1 ejemplar

Vestidos miniatura

Se encuentran como ofrendas en tumbas de mujeres. En algunos casos conforman, a su vez, parte de ajuares completos en miniatura, los que incluyen otras piezas, tales como mantas y sandalias.

Tomando en cuenta que estos vestidos representan a otros de mayor tamaño, aunque no necesariamente reflejan la manufactura de estos últimos, se han dividido considerando sus rasgos decorativos.

Monocromos. Es un vestido color salmón, RT 18571. Mide $14 \mathrm{~cm}$ de largo y $15 \mathrm{~cm}$ de ancho, tejido en algodón (Figura 2). 


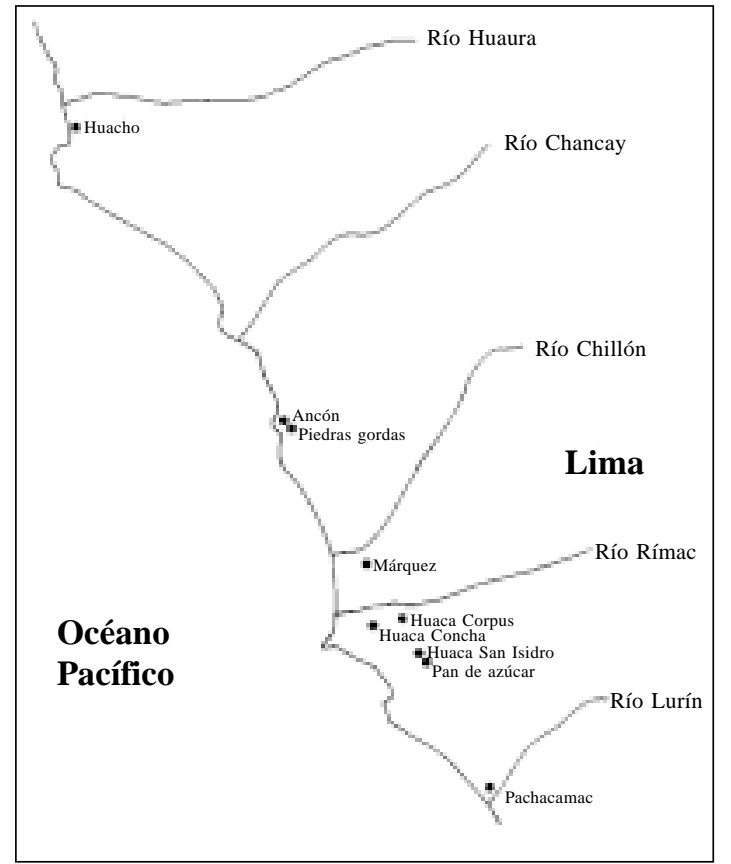

Figura 1. Mapa de la Costa Central peruana indicando los sitios arqueológicos donde se han encontrado vestidos femeninos. Basado en: Gayton 1955, Emery y King 1957, Stummer y Gayton 1958, Vanstan 1961 y Prümers 1998.

Está formado por un pañito rectangular de $31 \mathrm{~cm}$ de largo y $14 \mathrm{~cm}$ de ancho. Una vez terminado, se cosieron sus orillos de urdimbre mediante puntada envolvente. Después se cerró uno de sus bordes de trama, formando las aberturas para los brazos y el cuello. La costura de cierre quedó al frente, hacia el lado izquierdo del vestido (Figura 3).

Exhibe características que lo hacen único en la muestra: sus hilos sólo presentan torsión en $\mathrm{Z}$ y un teñido en color salmón, aunque originalmente debieron ser de color marrón claro. ${ }^{3}$ No tiene otra decoración. Otro detalle peculiar es que, al finalizar la costura de uno de los lados del vestido, ha quedado un hilo sobrante en el borde superior de la prenda, con el que se ha formado una especie de moño. En la colección de tejidos de Pachacamac se encuentran dos vestidos parecidos (Vanstan 1961), pero con hilos de algodón blanco natural, y retorcidos en $\mathrm{S}$. Otros vestidos tejidos con hilos teñidos, pero de mayor tamaño, se han encontrado en Ancón, donde se usaron hilos azules. Otro vestido más, procedente de la huaca Pan de Azúcar,

\footnotetext{
3 Los hilos presentan algunas zonas en color marrón claro.
}

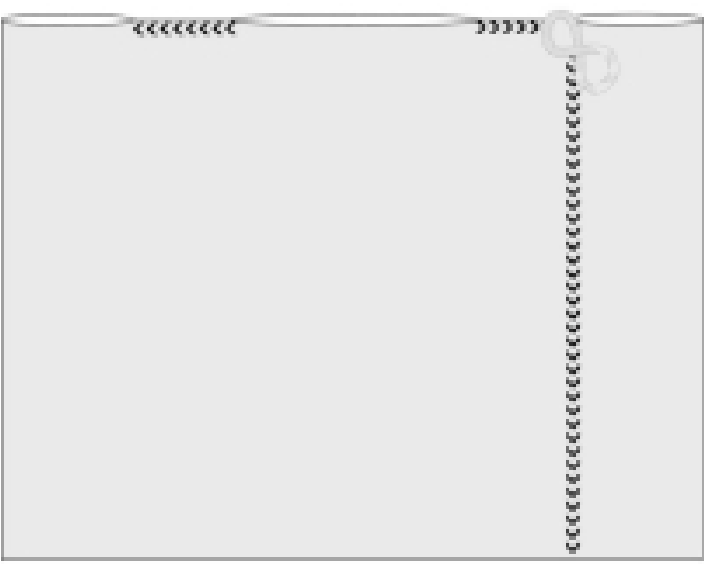

Figura 2. Vestido miniatura monocromo.
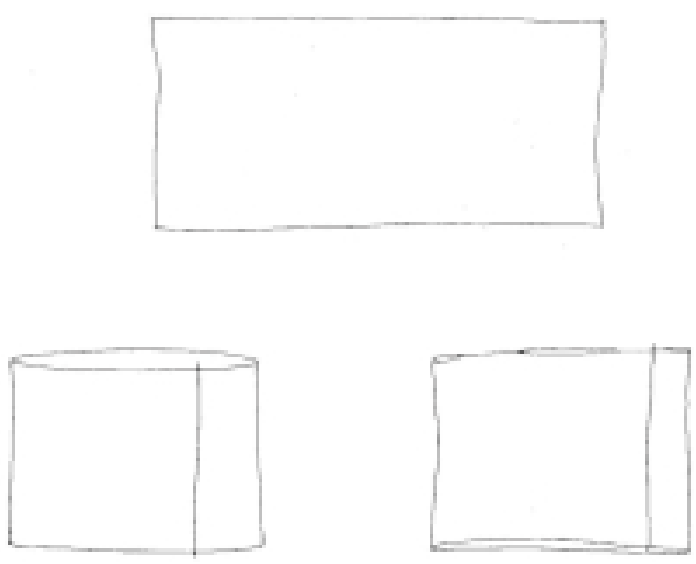

Figura 3. Construcción del vestido miniatura monocromo: paño extendido, doblez y costuras. Las urdimbres en sentido horizontal.

analizado por Heiko Prümers, fue tejido con hilos rojos y anaranjados (Prümers 1998: 218).

El contexto del vestido es desconocido. Su código indica que pertenece a las colecciones más antiguas del Museo.

Esta miniatura parece representar a los vestidos de una sola pieza ya que, al igual que éstos, no presenta ningún tipo de división, y es más ancha que larga.

De dos bandas horizontales. Son seis especímenes: RT 15211, 18483, 18484, 18489, 18491 y 26364. Como su nombre indica, presentan dos bandas horizontales, generalmente en colores blanco y marrón. Algunas de estas prendas presentan dos 
pliegues, uno a cada lado de la abertura del cue110 (Figura 4).

Para su confección se tejió un paño de algodón natural, en cara de urdimbre. Este paño, dos veces más largo que ancho, estaba dividido en dos secciones verticales, de colores contrastados. El paño se dobló por la mitad y se cosieron sus bordes de urdimbre. Esta es la razón por la cual los vestidos aparecen divididos en dos secciones horizontales. Finalmente, se hizo la costura para los hombros, dando forma también a los pliegues.

La mayor de estas prendas mide $23 \mathrm{~cm}$ de largo y $15.5 \mathrm{~cm}$ de ancho y la menor mide $15 \mathrm{~cm}$ de largo y $12 \mathrm{~cm}$ de ancho (Figura 5).

El contexto cultural de algunas estas prendas es conocido, ya que provienen de las excavaciones realizadas en Ancón. ${ }^{4}$

El registro de campo muestra que dos prendas (RT 26364 y 18489) provienen de una tumba múltiple de Ancón, y que se depositaron como ofrendas

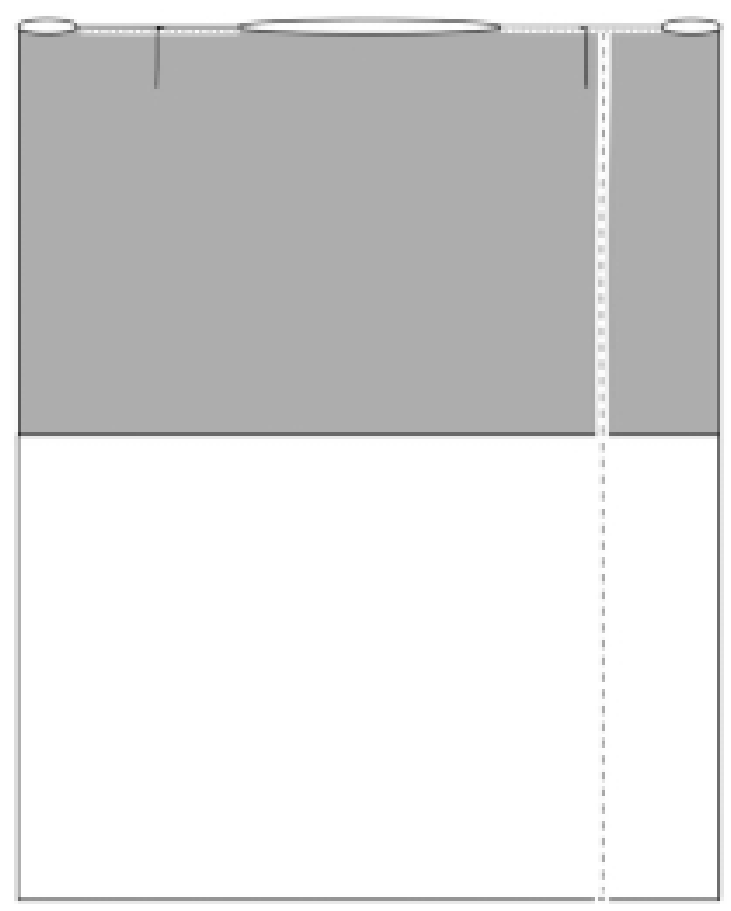

Figura 4. Vestido miniatura de dos bandas horizontales.

4 Sobre las excavaciones realizadas en Ancón, véase Ravinés (1977).
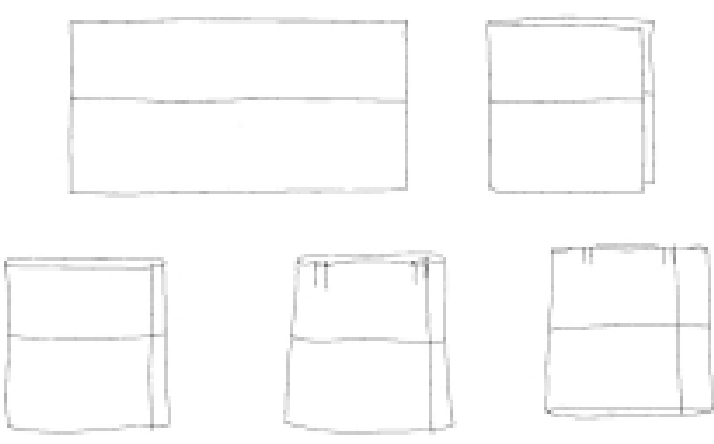

Figura 5. Construcción del vestido miniatura de dos bandas horizontales: paño extendido, doblez y cierre, conformación de los pliegues y costuras. Las urdimbres en sentido horizontal.

para una mujer de aproximadamente 45 años (Tumba 315 A1/P 4572). ${ }^{5}$ La prenda RT 26364 se encontró dentro de un paquetito, junto con otros cuatro vestidos miniatura, todos doblados en cuatro y colocados dentro de un paño mayor. Aunque la ubicación exacta del vestidito RT 18489 dentro de la tumba es confusa, éste debe haber estado dentro de uno de los paquetitos que contenían vestidos en miniatura.

El vestidito RT 15211 proviene de las especies recogidas del relleno de una tumba notable profanada, en Ancón (MNAAHP 1949 Ms). Por el tipo de restos asociados, esta tumba habría sido de filiación Chancay. ${ }^{6}$

Los vestidos RT 18483 y 18484 no tienen procedencia conocida. Del vestido RT 18491 sólo se conoce que proviene de Ancón.

Ina Vanstan (1961) estudió prendas semejantes de la colección de Uhle en Pachacamac y, aunque no pudo determinar con seguridad su contexto, planteó que eran representaciones de vestidos de mayor tamaño. Al respecto, en Ancón, en un mismo fardo, aparecen estos vestidos de dos piezas en sus tamaños miniatura y natural.

5 La tumba 315 es múltiple y en su interior se encontraron tres fardos: el de mayor tamaño correspondía al de una mujer mayor de 45 años (A1/P 4572), a los lados, el fardo de una joven de aproximadamente 12 años (A1/P 4571) y el de un niño de 8 años. Por los materiales asociados se le identificó como una tumba Chancay (Ccosi 1956 Ms, Gonzáles $1951 \mathrm{Ms})$.

6 Según el registro de campo los tejidos asociados mostraban motivos de aves en técnica de tapiz. 
De tres bandas horizontales. Son seis vestidos: RT 6812, 6813, 6814, 6815, 6816, 6822 y 6829. Son los vestidos miniatura más pequeños registrados. El mayor de ellos mide 7.5 por $7 \mathrm{~cm} \mathrm{y} \mathrm{el}$ menor 2.5 por $3,7 \mathrm{~cm}$. Muestran tres bandas horizontales, las de los extremos en un mismo color y la del centro en otro, haciendo contraste. Los colores usados fueron marrón, blanco y ante. Presentan costuras descuidadas en los hombros y a un costado, para cerrar el vestido (Figura 6).

Para su construcción se utilizó un solo paño tejido con hilos de algodón sin teñir, 2Z-S, en técnica llana, con tres listas en cara de urdimbre. Por lo general, el largo del paño es el doble de su ancho, lo que incide en la forma cuadrangular del vestido. Este paño, colocado con las listas en sentido horizontal, fue doblado por la mitad y se le aplicaron puntadas en el borde superior, formando las aberturas de los brazos y la cabeza. Posteriormente se hizo la costura de cierre lateral del vestido (Figura 7).

Cuatro de los vestidos registrados (RT 6814, 6815, 6816 y 6829) no presentan costura de cierre lateral, quizás se perdió o no se realizó.

Como ya se ha visto, estas prendas deben haber sido parte de las ofrendas colocadas en las tumbas de mujeres, y quizás componían ajuares mortuorios miniatura. Estos vestidos miniatura representarían a los vestidos mayores de tres piezas.

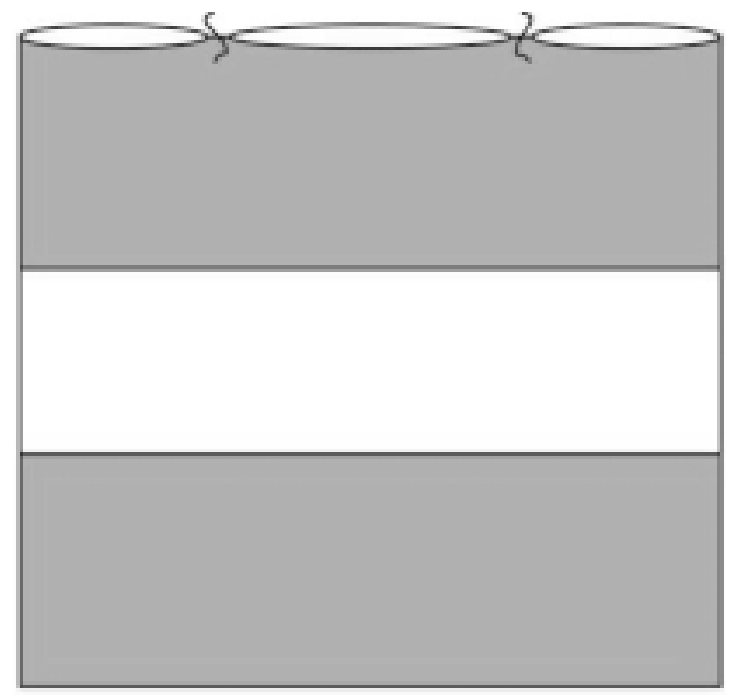

Figura 6. Vestido miniatura de tres bandas horizontales.
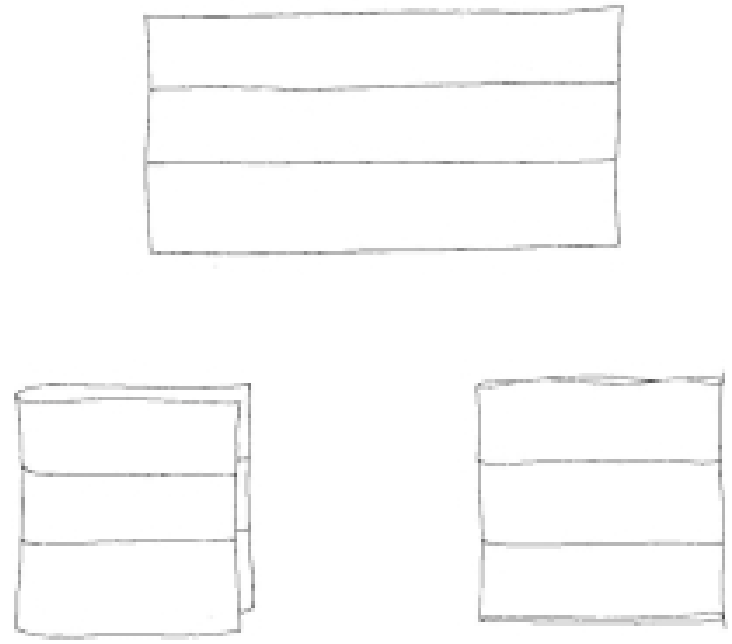

Figura 7. Construcción del vestido miniatura de tres bandas horizontales: Paño extendido, doblez y costuras. Las urdimbres en sentido horizontal.

La forma de estos vestidos puede causar que se les confunda con bolsas en miniatura. Para resolver este problema, se hace necesario revisar cuidadosamente sus costuras de cierre. Lamentablemente, no contamos con datos precisos sobre la procedencia de estos tejidos. Por sus características se pueden asignar al Período Intermedio Tardío de la Costa Central.

Vestidos de una pieza

Se caracterizan por haber sido realizados a partir de un paño angosto, por el uso exclusivo de algodón, por la presencia de bandas horizontales preferentemente situadas en los bordes inferior y superior, y la presencia de hilos de algodón teñidos que forman parte de las bandas decorativas. Por sus dimensiones, parecen ser prendas para niñas de aproximadamente 2 a 4 años. Este grupo está compuesto por cuatro especímenes:

a) Vestido completo RT 8677: compuesto por un paño angosto de algodón listado, con dos pliegues en la zona de los hombros. La costura se presenta al frente, hacia el lado izquierdo. Mide $43 \mathrm{~cm}$ de ancho y $30.5 \mathrm{~cm}$ de largo.

b) Vestido completo RT 28720: compuesto por un paño angosto de algodón marrón claro, con listas decorativas en el borde superior. La costura de cierre del vestido está en el extremo izquierdo. Mide $46 \mathrm{~cm}$ de ancho y $30 \mathrm{~cm}$ de largo. 
c) Vestido completo RT 4142: compuesto por un paño angosto de algodón marrón claro. Presenta listas decorativas en el borde superior e inferior, con seis pliegues en cada hombro. La costura de cierre del vestido está presente en la parte frontal del vestido, en el lado derecho, oculta entre los pliegues. Mide $64 \mathrm{~cm}$ de ancho por $48.5 \mathrm{~cm} \mathrm{de}$ largo.

d) Vestido completo RT 27805: compuesto por un paño angosto de algodón marrón claro. Presenta dos bandas decorativas en el borde superior. En el borde inferior, una banda ancha en color crema. La costura de cierre del vestido se encuentra en la parte central. Mide $66 \mathrm{~cm}$ de ancho por 46 cm de largo (Figura 8).

Los paños utilizados en la elaboración de los vestidos han sido realizados en tejido en cara de urdimbre, y las bandas decorativas en tejido de urdimbres complementarias. Se han usado hilos teñidos en colores verde y gris, pero un color constante en por lo menos tres de estos vestidos es el azul. En todos los casos, el resto de la prenda se tejió en algodón natural, blanco o marrón.

Los orillos de urdimbre del paño se unieron por costura. Esta última vendría a ser la costura de cierre del vestido, pudiendo quedar debajo del brazo izquierdo o en la parte central del vestido. En el caso que hubiera pliegues, quedaba oculta entre éstos. Después se procedió a coser un borde de trama para formar las aberturas para los brazos y la cabeza: en este momento se realizaron los pliegues de la zona de los hombros, presentes en algunas prendas (Figura 9).

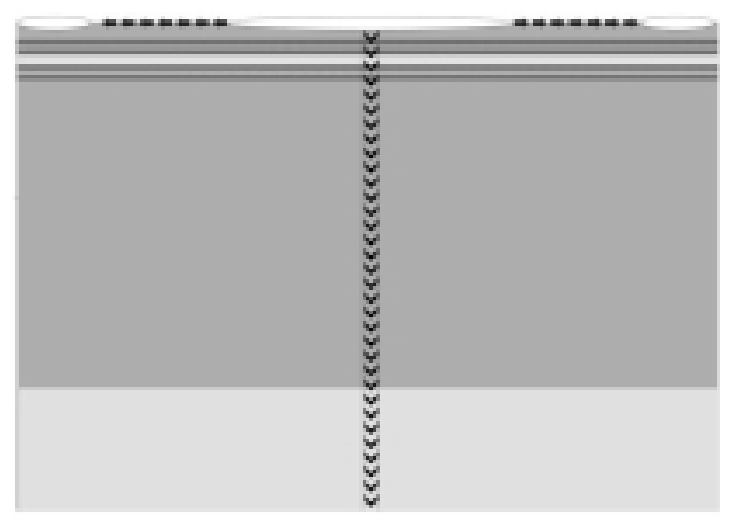

Figura 8. Vestido de una pieza, RT 27805.

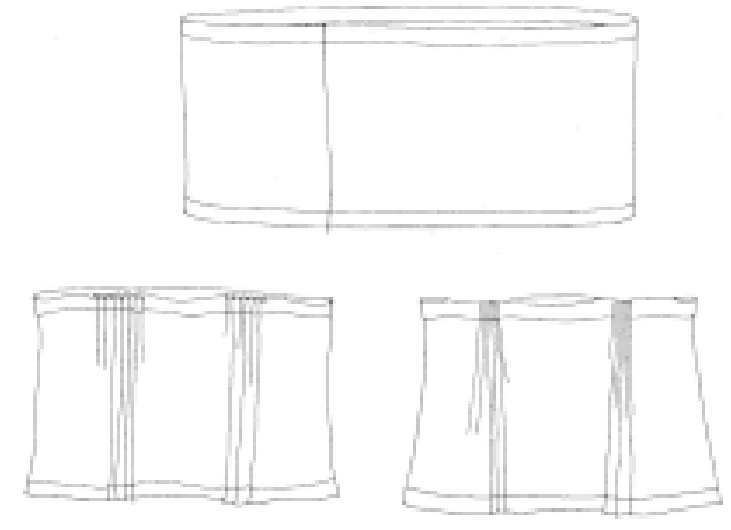

Figura 9. Construcción del vestido de una pieza, RT 4142: Paño cerrado, conformación de pliegues y costuras. Las urdimbres en sentido horizontal.

Una prenda de este tipo, pero sin ningún tipo de decoración, que evidenciaba mucho uso, se encontró en la tumba de una joven de 12 años ( $\mathrm{T}$ 315 A1/P 4571):

"Sp. 7: En la base del fardo aparece un tejido sirviendo de relleno sostén, una especie de unku de algodón blanco crema de textura fina con un largo de 0.80 por $0.60 \mathrm{~m}$. Consta de un solo paño. La prenda tuvo mucho uso con zurcidos y roturas. En regular estado" (Ccosi 1956 Ms: 80).

Las prendas de este tipo estarían destinadas para ser usadas por niñas, y algunas durante mucho tiempo, por ello presentan tantas reparaciones. En el caso de la niña de 12 años, creemos que si usaba esta prenda, debió complementarla con una falda, transformándola así en una especie de camiseta.

El dato correspondiente a los contextos de estos vestidos es mínimo. Sólo sabemos que dos fueron recolectados en Ancón ${ }^{7}$ (RT 8677 y 4142) y uno en la Huaca San Isidro $^{8}$ de Lima (RT 27805).

7 La prenda RT 8677 (A1/7701) se encontró al eliminar la porción inferior del basural Chancay en Ancón. La pieza RT 4142 (A1/7680) no corresponde con la descripción del inventario (MNAAHP 1949 Ms).

8 Con este nombre se conocía a dos huacas situadas al oeste de la Huaca Pan de Azúcar o Huallamarca, en las inmediaciones del actual Club de Golf de San Isidro. Actualmente ya no existen. Estaban construidas con adobitos rectangulares y adobones (Tello 1999: 69), característicos de los períodos tardíos en el valle de Lima. 
En el caso del cuarto vestido, la procedencia es desconocida (RT 28720).

Aunque los datos de campo indican que la mayoría de las prendas procede de superficie o de basurales, se les puede ubicar temporalmente en el Período Intermedio Tardío. Su distribución, al parecer, se extiende desde Ancón por el norte hasta Lima por el sur.

Vestidos de dos piezas

Vestidos divididos horizontalmente. Estos son vestidos grandes, con pliegues en la zona correspondiente a los hombros. Están compuestos por paños de diferente color, cuya unión horizontal se presenta como una línea curvada.

Heiko Prümers (1998) ha descrito vestidos semejantes, con pliegues a los lados del cuello y costura curvada en la unión de los paños. Sin embargo, los vestidos que él describe están compuestos por más de dos piezas, en otros colores y no presentan decoración pintada.

Tenemos tres especímenes:

a) Vestido completo, RT 3792: Compuesto por dos piezas. La superior es un tejido en cara de urdimbre, de algodón teñido en color azul. La inferior es un tejido en algodón natural color beige, con motivos pintados dispuestos dentro de paneles, de filiación Chancay. Presenta ocho pliegues en cada hombro Mide $111 \mathrm{~cm}$ de largo por $116 \mathrm{~cm} \mathrm{de}$ ancho (Figura 10).

b) Vestido incompleto, RT 1503: Compuesto por dos piezas. La superior es un tejido en cara de

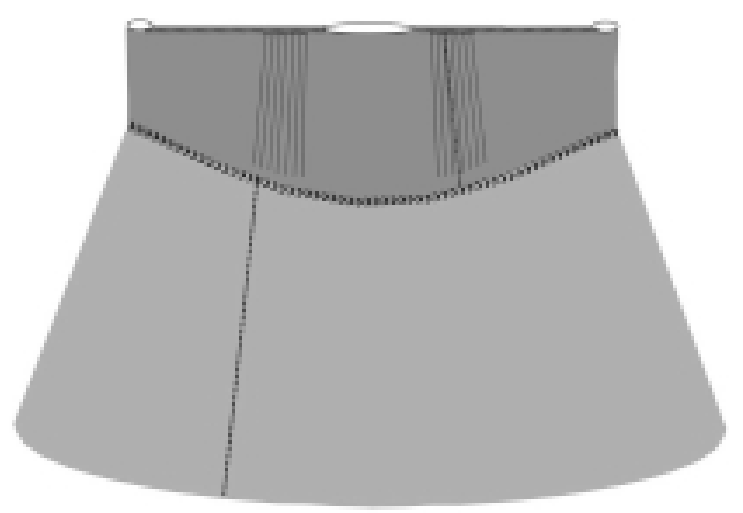

Figura 10. Vestido de dos piezas, RT 3792. urdimbre, de algodón teñido en color azul, decorado en la parte posterior con bordados de aves, peces y cabezas de serpientes entrelazadas. La inferior, en color beige, está incompleta, y no parece haber sido decorada. Presenta seis pliegues en cada hombro. Mide $150 \mathrm{~cm}$ de ancho y 72.5 $\mathrm{cm}$ de largo, aunque originalmente debió medir $120 \mathrm{~cm}$ de largo.

c) Fragmento de paño, RT 19619: Corresponde a la parte inferior de un vestido, en color beige. En su borde superior aún quedan restos de los hilos de costura. En este mismo borde se conservan trazas de los pliegues de la parte superior. Otra costura une sus bordes de urdimbre, como en los vestidos completos. Presenta una decoración semejante al vestido RT 3792 . Mide $71.5 \mathrm{~cm}$ de largo y $156.5 \mathrm{~cm}$ de ancho (cerrado). Unido al paño superior, debió formar un vestido de $120 \mathrm{~cm}$ de largo y $110 \mathrm{~cm}$ de ancho.

Los tres vestidos provienen de Ancón. El primer vestido procede de la momia MNAA 010, el segundo fue encontrado en superficie y del tercero aún no ha sido posible revisar su contexto exacto.

En los vestidos presentados es común el paño superior en color azul marino y el inferior en beige, eventualmente uno de los dos es decorado con motivos de filiación Chancay. La situación superior e inferior de los colores azul y beige no parece haber sido rígida, porque se ha encontrado un vestido femenino con la disposición inversa (véase más adelante).

En la elaboración de un vestido de dos piezas, los orillos de urdimbre del paño superior eran unidos con una puntada envolvente. Después, se cosía un borde de trama para formar las aberturas de los brazos y el cuello. En este momento se formaban los pliegues en los hombros. La costura de la unión de los orillos quedaba oculta bajo los pliegues.

En cuanto al paño inferior, sus orillos de urdimbre eran unidos mediante una costura, antes de su ensamble con el paño superior.

La unión de los paños fue realizada uniendo el borde de trama del paño inferior a la parte media del paño superior, quedando la costura paralela al borde de trama inferior. Si bien la línea de unión de los paños tenía un sentido horizontal, no era regular, y resultaba en una línea curvada (Figura 11). 
En uno de los cuadernos de disección de los fardos de Ancón se describe un vestido de dos piezas con la parte superior en color marrón claro y la inferior en color azul (Ccosi $1956 \mathrm{Ms}$ : 136). De $1.04 \mathrm{~m}$ de ancho por $1.06 \mathrm{~m}$ de largo, estaba cubriendo un fardo (T 315 A1/P.4571), quedando su paño inferior como base, por lo cual esta parte se deterioró. En otros vestidos estudiados hemos encontrado un daño similar, pudiendo ser ésta la causa.

En otra de estas prendas las aberturas para las manos son muy pequeñas: sólo dejan salir cuatro dedos, ${ }^{9}$ lo que sugiere un uso para actividades limitadas, o que se tejieron para servir como envoltorio funerario. En el caso del vestido bordado se nota una unión presurosa del paño inferior. Por otra parte, los bordados del paño superior tampoco se concluyeron: un diseño de serpientes entrelazadas así lo muestra. La forma de unión de los paños causó el cubrimiento total del bordado inferior del paño superior. Heiko Prümers (1998: 224225) ha interpretado este cubrimiento como una reutilización de tejidos para formar un vestido.

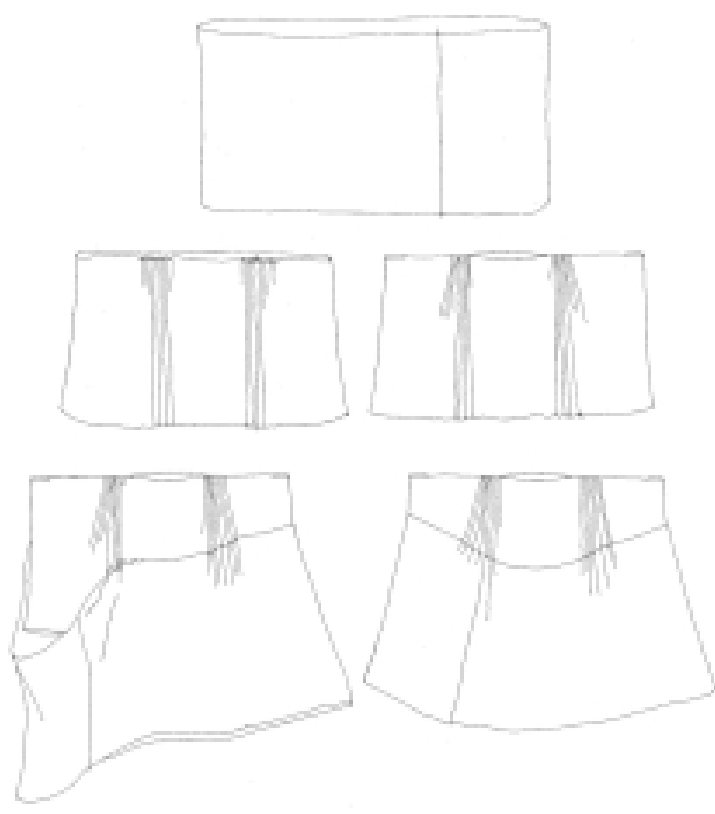

Figura 11. Construcción del vestido de dos piezas, RT 3792: paño superior cerrado, conformación de los pliegues y costuras del borde superior, ensamblaje con el paño inferior cerrado y configuración final. Las urdimbres en sentido horizontal.

$9 \quad$ El primer vestido presenta aberturas de 6 y $7 \mathrm{~cm}$ para las manos.
Vestidos de tres piezas

Se trata de un vestido grande, RT 17875, procedente de Ancón. Está compuesto por tres bandas angostas de tejido llano ralo, elaboradas con hilos de lana tosca y poco retorcida. El paño que corresponde al borde superior del vestido presenta listas en color rojo y morado, los otros dos paños son de color marrón. El paño superior es el de mayor tamaño y el inferior es el menor de los tres. Esto da al vestido un efecto de hombros anchos, recto hacia abajo, sin el vuelo de los vestidos antes mencionados (Figura 12).

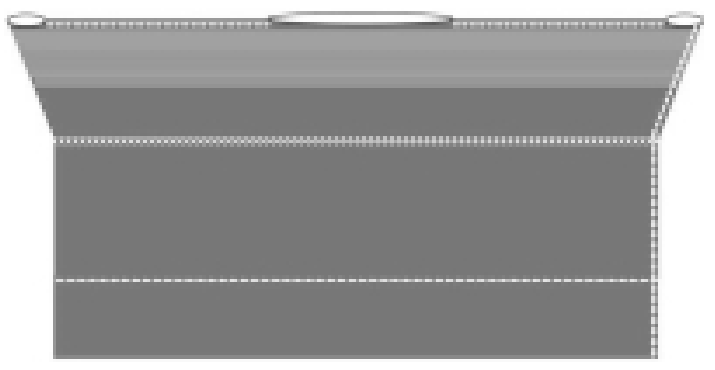

Figura 12. Vestido de tres piezas.

La unión de los paños, por sus bordes de trama, se hizo en punto corrido, con hilo de algodón blanco, sin mucho cuidado. La diferencia de sus longitudes ha producido la aparición de pequeñas ondas. El paño obtenido de la unión de los tres, de forma trapezoidal, fue doblado por la mitad y se unieron sus bordes de urdimbre. Posteriormente se cerró el borde de trama que coincide con la decoración listada, dejándose las aberturas para los brazos y la cabeza (Figura 13).

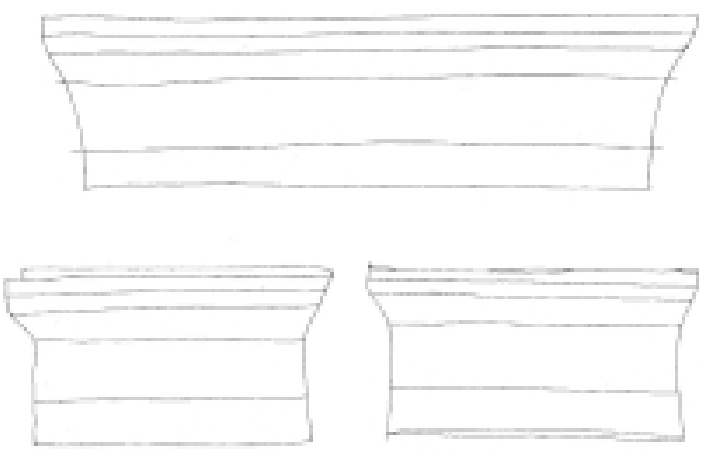

Figura 13. Construcción del vestido de tres piezas: paño compuesto extendido, doblez y costuras de cierre. Las urdimbres en sentido horizontal. 
Considerando que es de lana gruesa, este vestido debe haber sido usado en la época invernal de la costa. En la colección textil del Museo Nacional se encuentran bandas semejantes a las que componen este vestido, quizás partes de vestidos similares que perdieron las costuras de unión. En los informes de disección de las momias de Ancón estas mismas bandas se registran asociadas a vestidos de algodón con pliegues en los hombros.

Los envoltorios cuadrangulares de algunos entierros en Ancón presentan tres bandas horizontales en colores marrón y blanco (Ccosi 1957 Ms: 256). Podría tratarse de vestidos reutilizados como envoltorios.

\section{Otros vestidos femeninos}

En la colección textil del Museo Nacional hemos encontrado tres vestidos femeninos adicionales. Aunque comparten algunos rasgos con los vestidos ya descritos, sobre todo la costura en la zona de los hombros, no pertenecen a la misma tradición. El primero de ellos podría ser un antecedente de los tipos definidos anteriormente. El segundo, de contexto desconocido, proviene de una tradición donde se usa un telar más ancho. El tercero, procedente de Pacatnamú, tiene cinco aberturas en el borde superior.

Vestido de dos piezas con una banda vertical

Se trata de un especimen proveniente de Ancón, RT 5370. A diferencia de los vestidos anteriores, que presentan bandas decorativas horizontales y costuras en puntadas realizadas con hilos de algodón, este vestido presenta, en la parte frontal, una banda decorativa vertical en la parte central, con motivos de peces y cabezas de serpientes. $\mathrm{La}$ costura de los hombros, realizada con lana roja, también es decorativa. La parte posterior del vestido exhibe decoración pintada (Figuras 14 y 15).

El vestido fue compuesto con dos paños de algodón. Cada uno de ellos con una banda decorativa horizontal en uno de sus orillos de urdimbre. Ambos paños fueron cosidos por su borde de trama para formar un paño mayor, quedando sus bandas decorativas alineadas. Este paño resultante se dobló por la mitad y se unieron sus orillos de urdimbre mediante una costura muy fina. Después se cosió un borde de trama para formar las aberturas de los brazos y la cabeza. La costura de cierre del vestido quedó en la parte central, junto con la banda decorativa vertical formada por la unión de las bandas de los dos paños (Figura 16). Una vez terminado el vestido, en su parte posterior, se pintaron círculos y listas horizontales en color púrpura.

Este vestido fue revisado por Desrosiers y Pulini (1992), y a partir de él identificaron otros frag-

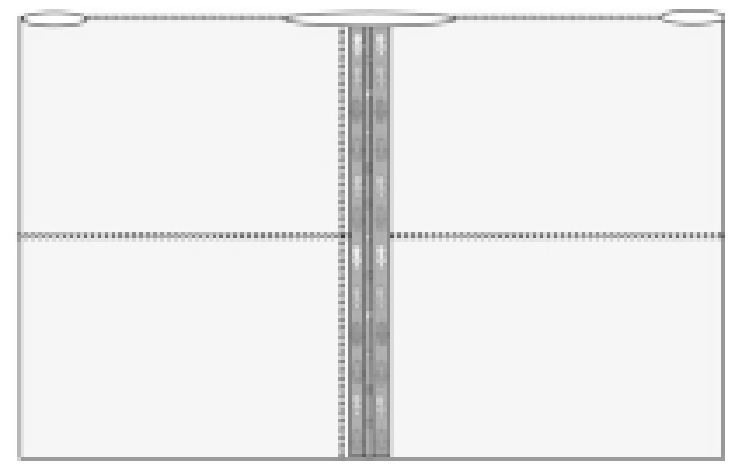

Figura 14. Vestido de dos piezas con una banda vertical.

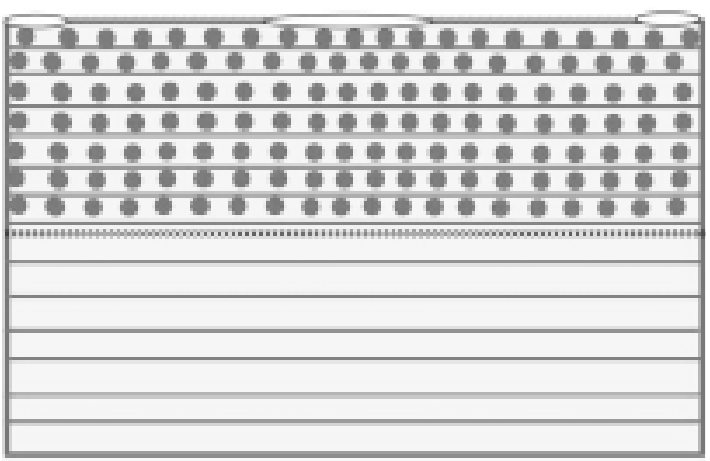

Figura 15. Decoración pintada del vestido.

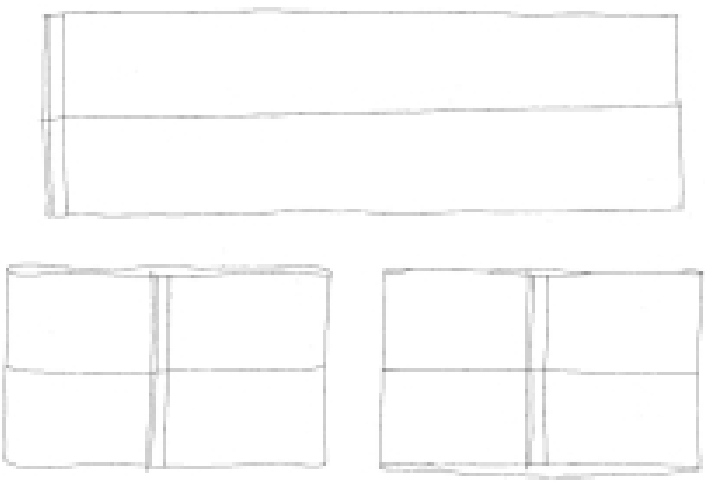

Figura 16. Construcción del vestido de dos piezas con una banda vertical: paño compuesto extendido, doblez, cierre y costuras del borde superior. Las urdimbres en sentido horizontal. 
mentos correspondientes a vestidos similares. Ilaria Pulini ha clasificado estas prendas dentro de una tradición textil denominada "tejidos policromos con fondo rojo", fechada hacia el Horizonte Medio 3 y 4 y los inicios del Período Intermedio Tardío. Pulini (2000) plantea la posición más temprana de estos tejidos con respecto a los tejidos Chancay.

Este vestido sería un antecedente de los vestidos tardíos, pues en él ya se observa el uso de dos paños angostos, productos del telar de cintura, unidos por sus orillos de trama para formar un paño mayor, y las costuras para el cierre del vestido y la zona de los hombros. Estas particularidades, que podrían ser aún más tempranas, subsistieron como un rasgo local durante el Horizonte Medio.

Vestido de dos piezas, diseño envolvente

Por sus características, esta prenda (RT 30533) procedería de la Costa Sur. Presenta una estructura envolvente, carece de la costura de cierre del vestido y de la división horizontal. Por el contrario, muestra una división vertical como producto de la unión de los paños que lo conforman. De otra parte, mientras el paño más ancho de la Costa Central mide $70 \mathrm{~cm}$, los paños de este vestido alcanzan los $90 \mathrm{~cm}$ de ancho y los $112 \mathrm{~cm}$ de largo (Figura 17).

La prenda fue confeccionada con dos paños de algodón en tela llana, uno rectangular de color beige claro y otro cuadrangular de color azul. En un borde de trama ambos presentan, como única decoración, una lista fina de color rojo para el paño marrón, y de color azul oscuro para el paño azul. Estos paños se unieron por su borde de urdimbre para formar un paño mayor, que al envolverse sobre sí, forma el vestido. El cruce del paño sobre sí mismo se extiende de brazo a brazo, quedando el paño color marrón expuesto y el paño azul casi oculto por el primero, salvo hacia el lado izquierdo del vestido, donde se ha dejado expuesta la unión de los paños. Como anotamos, no existe costura de cierre del vestido. Sólo se aplicaron costuras en la zona de los hombros las que, a su vez, permiten mantener la posición del paño (Figura 18).

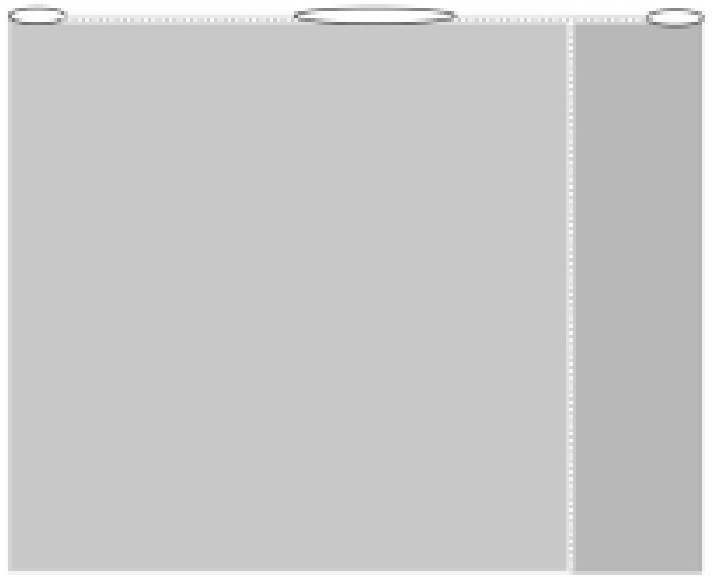

Figura 17. Vestido de dos piezas de diseño envolvente.

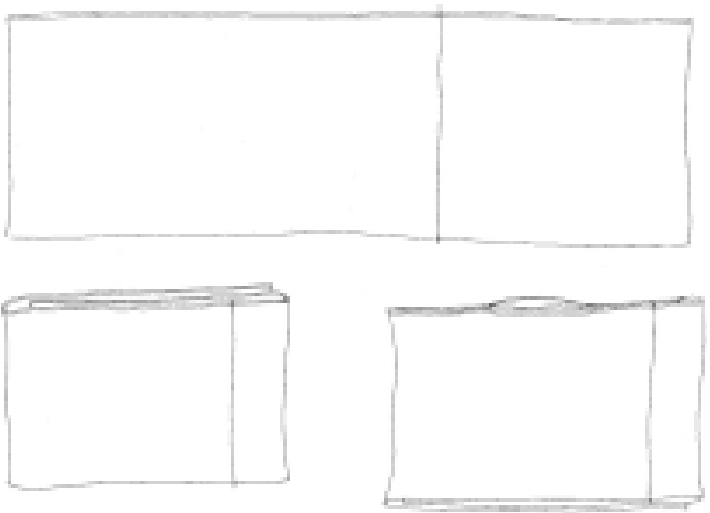

Figura 18. Construcción del vestido de dos piezas de diseño envolvente: Paño compuesto extendido, disposición envolvente y costuras del borde superior. Las urdimbres en sentido horizontal.

Vestido de más de dos piezas, con cinco aberturas

Se trata de la parte superior de un vestido, RT 22296. Mide $124.5 \mathrm{~cm}$ de ancho y $18.5 \mathrm{~cm}$ de alto, por lo que actualmente llega solamente hasta el busto.

Esta prenda procede de Pacatnamú, de las excavaciones realizadas por Uhbelode-Doëring. Aunque incompleta, habría estado compuesta por al menos dos paños, y sería de tipo envolvente, sin costura de cierre.

Presenta cinco aberturas horizontales en el borde superior. La central para la cabeza y las más extremas para los brazos. Las dos aberturas restantes serían para los hombros. No hay dudas sobre la disposición de estas aberturas, ya que la con- 
servación de los hilos de costura es buena, y presentan nudos tanto en su inicio como en su fin (Figura 19).

Está formado por una banda de $285 \mathrm{~cm}$ de largo por $18.5 \mathrm{~cm}$ de ancho, tejida en algodón blanco, envuelta sobre sí misma para formar el cuerpo del vestido, quedando el cruce justo debajo de la abertura de la cabeza. En su borde inferior presenta una zona más clara, de $0.5 \mathrm{~cm}$ de ancho, producto del contacto con otro paño, al cual estuvo unido por puntadas que aún se conservan (Figura 20).

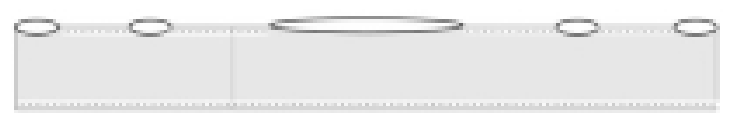

Figura 19. Vestido con cinco aberturas.

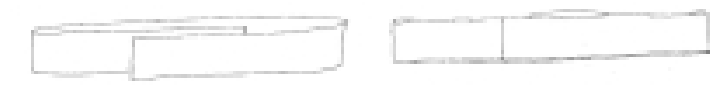

Figura 20. Construcción del vestido con cinco aberturas: paño extendido, disposición envolvente y costuras del borde superior. Las urdimbres en sentido horizontal.

\section{Conclusiones}

La vestimenta femenina en la Costa Central peruana durante el Período Intermedio Tardío presenta características comunes a la vestimenta femenina del resto del Area Andina, como son el uso de aberturas horizontales para los brazos y la cabeza. Sin embargo, presenta caracteres propios del desarrollo de una tradición local, dentro de la cual subsisten algunas diferencias como producto de la elaboración de los vestidos por distintas comunidades o por influencias producto de la interacción con otros grupos foráneos.

En lo que respecta al período y lugar que nos ocupa, la tradición en la vestimenta femenina está caracterizada por:

- El uso del algodón como materia prima.

- El uso del telar de cintura para tejer los paños que conformarán el vestido, paños que por este motivo son angostos y largos.
- Preferencia por el tejido en cara de urdimbre.

- Unión de los paños a todo lo largo, y su uso en sentido horizontal.

- Costura lateral para el cierre del vestido.

- Decoración en sentido horizontal, nunca vertical.

- Formación de pliegues a los lados del vestido, para producir un mayor vuelo.

Sin embargo, estos caracteres podrían tener una profundidad temporal mayor. Se han encontrado evidencias de ellos en vestidos femeninos del Horizonte Medio.

Los vestidos en miniatura, que a menudo se presentan en conjuntos, componiendo verdaderos ajuares, permiten observar, a través de ellos, la composición de los vestidos mayores de una, dos $\mathrm{y}$ tres piezas.

Los vestidos de una sola pieza estarían destinados para las niñas, mientras que los de dos y tres piezas serían para las mujeres que habrían superado la pubertad.

En la costa se usaron vestidos de lana en las épocas más frías. La pertenencia de los mismos a la tradición que nos ocupa se ve reforzada porque se han encontrado bandas de la misma calidad y colores en tumbas de mujeres donde también hay vestidos de algodón de dos piezas y pliegues.

Agradecimientos Al doctor Luis Guillermo Lumbreras por autorizarme el acceso a las colecciones del Museo Nacional de Arqueología, Antropología e Historia del Perú, a Elba Manrique, jefa del Departamento Textil, a Mirtha de La Cruz por las facilidades para la revisión de los tejidos, a Juan Peralta, jefe del Departamento de Registro y Catalogación, y Fanny Montesinos por proveerme de los datos de procedencia, a María Eugenia, Rocío y Ernesto del Archivo Documental por facilitarme la revisión de los registros de campo y gabinete. A María Ysabel Medina por todo el apoyo brindado, y a Pedro Novoa por revisar este texto. 


\section{LA VESTIMENTA FEMENINA EN LA COSTA CENTRAL DEL PERU...}

\section{REFERENCIAS CITADAS}

CCOSI, L., 1956 Ms. Cuaderno 1 de disección de los fardos de Ancón 1. Archivo Documental del Museo Nacional de Arqueología, Antropología e Historia del Perú (AT-0612001-MNAAHP), Lima.

1957 Ms. Cuaderno 2 de disección de los fardos de Ancón 1. Archivo Documental del Museo Nacional de Arqueología, Antropología e Historia del Perú (AT-0622001-MNAAHP), Lima.

DESROSIERS, S. e I. PULINI, 1992. Tessuti precolombiani. Musei Civici di Modena. Ed. Franco Cosimo Panini, Modena.

EMERY, I. y E. KING, 1957. Additional examples of an unusual Peruvian shirt type. American Antiquity 23 (1): 71-74.

GAYTON, A., 1955. A new type of ancient Peruvian shirt. American Antiquity 20 (3): 263-270.

GONZALES, M., 1951 Ms. Diario de los trabajos arqueológicos en Ancón 1. Tomo IX. Archivo Documental del Museo Nacional de Arqueología, Antropología e Historia del Perú (AT-026-2001-MNAAHP), Lima.

MNAAHP, 1949 Ms. Cuaderno 4 de inventario de especies arqueológicas Ancón 1. Archivo Documental del Museo Nacional de Arqueología, Antropología e Historia del Perú (AT-004-2001-MNAAHP), Lima.

PULINI, I., 1992. Tipi tessili de la costa centrale peruviana tra Horizonte Medio e Periodo Intermedio Recente. En
Tessuti precolombiani, Desrosiers, S. e I. Pulini (Eds.), pp. 61-83. Musei Civici di Modena. Franco Cosimo Panini, Modena.

- 2000. Tejidos policromos con fondo rojo: Una tradición textil de la costa central peruana entre finales del Horizonte Medio y principios del Período Intermedio Tardío. Actas de la I Jornada Internacional sobre Tejidos Precolombinos, pp.110-126. Universitat Autònoma de Barcelona, Barcelona.

PRÜMERS, H., 1998. Un nuevo tipo de camisa del antiguo Perú. En 50 años de estudios americanistas en la Universidad de Bonn. Nuevas contribuciones a la arqueología, etnohistoria, etnolingüística y etnografía de las Américas. Bonner Amerikanistische Studien, 30: 217-237.

RAVINES, R., 1977. Prácticas funerarias en Ancón (primera parte). Revista del Museo Nacional, T. XLIII: 1-327, Lima.

STUMMER, L. y A. GAYTON, 1958. A horizontal-necked shirt Marques, Perú. American Antiquity 24 (2): 181-182.

TELLO, J., 1999. Walla marka. Cuadernos de Investigación del Archivo Tello $N^{\circ}$ 1: Arqueología del valle de Lima. P. Novoa (Ed.), pp. 65-79. Museo de Arqueología y Antropología de la Universidad Nacional Mayor de San Marcos, Lima.

VANSTAN, I., 1961. Miniature peruvian shirts with horizontal neck openings. American Antiquity 26 (4): 524-531. 